\title{
Understanding complementarities among different forms of innovation
}

\author{
Pedro Torres \\ University of Coimbra, CeBER, Faculty of Economics \\ Av. Dias da Silva, 165 \\ 3004-512 Coimbra - Portugal \\ E-mail: pedro.torres@uc.pt \\ Mário Augusto \\ University of Coimbra, CeBER, Faculty of Economics \\ Av. Dias da Silva, 165 \\ 3004-512 Coimbra - Portugal \\ E-mail: maugusto@fe.uc.pt
}

Corresponding author: Pedro Torres

Funding : This work has been funded by national funds through FCT - Fundação para a Ciência e a Tecnologia, I.P., Project UIDB/05037/2020

The final version of this article is available online at https://www.emeraldinsight.com/doi/pdfplus/[https://doi.org/10.1108/EJIM-01-2019-0012]

This manuscript version is made available under the under the Creative Commons Attribution Noncommercial International Licence 4.0 (CC BY-NC 4.0). Reuse is allowed in accordance with the terms outlined by this licence 


\title{
Understanding complementarities among different forms of innovation
}

\begin{abstract}
Purpose - This study aims to better understand complementarities-in-performance of three forms of innovation: product innovation, process innovation, and organizational innovation. Additionally, complementarities-in-use for product innovation are examined, considering an additional condition: manufacturing flexibility.

Design/methodology/approach - Using data from 223 unlisted Portuguese industrial firms, and a fuzzy-set qualitative comparative analysis ( $f \mathrm{QCA}$ ), different combinations of different forms of innovation were examined to identify complementarities-in-performance and complementarities-in-use.

Findings - Though the configurational analysis a path to achieve high performance was uncovered, which includes the presence of both product and organizational innovation. The study also reveals that the joint absence of two conditions (from the three that were considered in the analysis) can lead to low performance. This result indicates that the relationships among the antecedent conditions are non-linear. The configurational analysis also shows that the combination of manufacturing flexibility with either process innovation or organizational innovation can lead to high product innovation. This result confirms that manufacturing flexibility is an important condition for product innovation.
\end{abstract}

Research limitations/implications - The empirical evidence reported in this paper may be influenced by the definitions that were considered. Further conceptual and empirical research is encouraged to corroborate (or refute) or consolidate the findings presented herein. Moreover, although the obtained results present a high empirical coverage, other antecedent conditions beyond the scope of this study can also play an important role; for instance, marketing could influence innovation performance. Furthermore, radical innovation was not distinguished from incremental innovation when analyzing firm performance.

Practical implications - This study provides some clues for policy-makers that aim to enhance firm performance through innovation. Managers should focus on both organizational and technological innovation, in particular product innovation, to improve firm performance. Moreover, they should be aware of the complementarities-in-use for product innovation. Considering the importance of developing product innovation to 
enhance performance, firms should promote high levels of product innovation. To achieve this outcome, manufacturing flexibility should be present.

Originality/value - Focusing on a very complex and still under researched topic, this study contributes to the complementarities literature in several ways. This study employs a configurational approach to better understand complementarities and to integrate technological and organizational innovation. By taking this approach this study acknowledges the existence of non-linearity and identifies not only the strategies to achieve high performance, but also the configurations that lead to low performance.

Keywords: Complementarities; organizational innovation; product innovation; process innovation; manufacturing flexibility; performance.

\section{Introduction}

The importance of innovation for firms' survival and growth is widely acknowledged (e.g. Visnjic et al., 2016; Jong, 2013). However, the stream of innovation research that focused on complementarities is still in its infancy (Hullova et al., 2016). Although the existence of complementarities among different forms of innovation has been acknowledged long ago (e.g. Schumpeter, 1934), complementarity research has not progressed enough to constitute a theory (Ennen and Richter, 2010). Despite the progress that has been made in understanding the concept of complementarities (e.g. Ballot et al., 2015; Guisado-González et al., 2017), it is still an under-researched topic (Hullova et al., 2019). Furthermore, the literature suggests that the study of technological and organizational innovation should be integrated (e.g. Hollen et al., 2013; Battisti and Stoneman, 2010), which does not occur often.

Complementarities research has followed two different main approaches, which were termed complementarities-in-performance and complementarities-in-use by Ballot et al. (2015). While the former approach tests the economic value of combining different activities and practices (e.g. Pisano and Wheelwright, 1995), the latter investigates the linking between two sets of activities and suggests that one practice often requires other practice (e.g. Kurkkio et al., 2011). Regarding complementarities-in-performance, based on data provided by the Community Innovation Surveys (CIS), previous studies used interaction analysis (e.g. Sapprasert and Clausen, 2012) and cluster methodologies (e.g. 
Battisti and Stoneman, 2010), but these approaches imply linear combinations of the underlying practice variables; thus, they failed to capture the "non-linear interaction effects that are at the heart of the complementarity concept" (Ballot et al., 2015, p. 219). Other studies employed super-modularity methods (e.g. Ballot et al., 2015; Doran, 2012); however, the results were in great extent inconclusive. Ballot et al. (2015) focused on conditional tests (because unconditional tests were inconclusive) and suggested that the complementarity between two innovation forms was conditional to the presence/absence of the third form. However, this requirement is an important limitation. Evangelista and Vezzani (2010) suggested that the joint introduction of product, process, and organizational innovation provides a clear competitive advantage to both manufacturing and service firms. But, they also highlight that although competitive advantage arises from the combination of different forms of innovations, different types of strategy are feasible. Therefore, it can be hypothesized that to achieve high levels of performance maybe it is not necessary to invest in the three forms of innovation: product, process, and organizational innovation. Moreover, there is also some controversy regarding the role of organizational innovation. For instance, while Evangelista and Vezzani (2010) found that organizational innovation plays an important role as a driver of firms' performance, Nguyen-Thi and Mothe (2010) suggested that organizational innovation does not enhance firms' innovative performance, although it may lead to a higher propensity to introduce new or improved products or services. Thus, further research has been encouraged to study the links among different forms of innovation.

This paper contributes to bridging the gap between technological and organizational research streams, which are usually two separate bodies of literature, and investigates the complementarities-in-performance of three forms of innovation: product innovation, process innovation, and organizational innovation. The main objective is to identify "winning strategies" through the combination of different forms of innovation. The study uses a configurational perspective that takes into account non-linear relationships, and employs fuzzy-set qualitative comparative analysis (fsQCA). To the best of our knowledge, this methodological approach has not been used to date for analysing complementarities of innovation. Additionally, this paper investigates complementarities-in-use for product innovation, considering an additional condition: manufacturing flexibility. fsQCA is a method that has recently experienced a significant increase in the number of applications (see, for example, Berger, 2016), which helps to build and elaborate theory regarding whether a condition is necessary and/or sufficient for an outcome of interest to occur (McKnight and Ziestma, 2018). This technique examines the relationships between the 
outcome and all possible combinations of the binary states (presence/absence) of its antecedent conditions, enabling unconditional testing of complementarities.

Focusing on a complex and still under researched topic, this study contributes to the complementarities literature in several ways. First, the configurational analysis uncovered a path to performance, which includes the presence of both product and organizational innovation; process innovation could be either present or absent. Second, taking a novel angle and looking for the conditions that led to low performance, the study reveals that the joint absence of two conditions (from the three that were considered in the analysis) can lead to this outcome. This result indicates that the relationships among the antecedent conditions are non-linear. Third, the configurational analysis shows that the combination of manufacturing flexibility with either process innovation or organizational innovation can lead to high product innovation. This result confirms that manufacturing flexibility is an important condition for product innovation. These new insights provide some clues for policy-makers that aim to enhance firm performance through innovation.

The paper is structured as follows: after this introduction, Section 2 presents the conceptual background and the configurational approach, setting out the tenets for theory construction. Section 3 describes the employed research design. Then, the results and configurational analysis are presented in Section 4. Finally, in Section 5 the results are discussed and the main conclusions and implications are highlighted.

\section{Background, configurational approach, and tenets}

\subsection{Different forms of innovation}

Innovation contributes to value creation (e.g. Bos-Brouwers, 2010) and the literature has recognized its importance for manufacturing firms' survival and growth (e.g. Visnjic et al., 2016; Jong, 2013). Innovation is a multifaceted phenomenon that includes the "production or adoption, assimilation, and exploitation of a value-added novelty in economic and social spheres; renewal and enlargement of products, services, and markets; development of new methods of production; and establishment of new management systems" (Crossan and Apaydin, 2010, p. 1155). Thus, innovation takes many forms.

The innovation literature has identified two main sets of factors, which were termed “organizational innovation" and "technological innovation" (Battisti and Stoneman, 2010). The former involves, for instance, new management practices, new marketing concepts, new corporate strategies, and new business models. The latter encompasses process and product 
innovation, it relates to "the implementation of an idea for a new product or service or the introduction of new elements in an organization's production process or service operation" (Damanpour and Evan, 1984, p. 394). While "technological innovation" mainly introduces changes in the firm's operating system, "organizational innovation" mainly influence the firm's management systems (Damanpour and Aravind, 2011). Previous studies have mainly focused on "technological innovation", but it has been noted that the adoption of a single type of innovation or even the adoption of a set of innovations of only one type would not enable firms to take full advantage of the benefits of innovation (Damanpour and Arayind, 2011). Moreover, some studies highlighted the advantages of combining technological and organizational innovation (e.g. Hollen et al., 2013). In fact, the literature suggests that "organization innovation" can be a prerequisite or a facilitator of the implementation of "technological innovation" (e.g. Armbruster et al., 2008). With the emergence of internetbased technologies, changes in hierarchical structures and management practices, such as decentralized authority, teamwork, and incentives, become even more important (Cozzarin, 2017). Thus, the analysis of innovation beyond the technological domain can shed some light on firms' innovation strategies and performance (Evangelista and Vezzani, 2010).

Recently, the joint adoption of organizational and technological innovation has been object of some research (e.g. Guisado-González et al., 2017; Hervas-Oliver and SempereRippol, 2015; Evangelista and Vezzani, 2010), but this research topic is still under developed. Organizational innovation has been considered a relevant condition to support product and process innovation (e.g. Lam, 2005). It has also been suggested that the joint introduction of technological and organizational innovations can reinforce complementarities between product and process innovation (e.g. Le Bas et al., 2015; Evangelista and Vezzani, 2010). Furthermore, it has been acknowledged that process and organizational innovation follow innovation patterns that differ from product innovation (Lopez-Valeiras et al., 2016). But, it was also suggested that changes in organizational practices can lead to an appropriate culture and environment to stimulate other types of innovations (Wong, 2013). In spite of the theoretical support for considering organizational innovation an antecedent condition of product innovation, some studies did not found a relation between organizational innovation and product innovation (e.g. Guisado-González et al., 2017). Therefore, the role of organizational innovation remains unclear.

The notion that the joint and simultaneous adoption of different types of innovation can lead to a complementarity effect on company' performance is routed in the integrative approach, which has gained momentum recently (e.g. Ballot et al., 2015; Battisti and 
Stoneman, 2010; Damanpour, 2010). In contrast, the distinctive view suggests that there is no interaction between product and process innovation because they are influenced by different conditions and lead to different outcomes (e.g. Fritsch and Meshede, 2001). While process innovation emphasizes efficiency and usually focus on cost savings, product innovation is more about effectiveness and focus on differentiation (Kahn, 2018). A third approach, termed the product-process framework, suggests that the relationship between product and process innovation is substitutive. This approach, which was proposed by Hayes and Wheelwright $(1979 \mathrm{a}, \mathrm{b})$, implies a trade-off between product innovation and process innovation. But, it has been suggested the trade-off could be eliminated our minimized by organizational innovation (e.g. Dean and Snell, 1996), thereby transforming a substitutability relationship between these two forms of innovation into an independent or complementary relationship. More recent research suggested that "none of the three approaches is universally applicable to all pairs of relationships between different types of innovation" (Guisado-González et al., 2017, p. 456), which calls for further research. Furthermore, complementarities' research has followed two separate research streams: complementarities-in-use and complementarities-in-performance. Recent research suggest that a holistic approach could yield a better understanding and advance complementarity research (Hullova et al., 2019).

\subsubsection{Organizational innovation}

Organizational innovation is a broad concept that encompasses strategies, structural, and behavioural dimensions (Le Bas et al., 2015). According to the Organization for Economic Co-Operation and Development (OECD) organizational innovation corresponds to "the implementation of a new organizational method in the firm's business practices, workplace organization or external relations" (OECD, 2005, p.51). This definition is often used, given the lack of consensus in the conceptualization of organizational innovation. The term "organizational innovation" was first introduced by Trist and Bamforth (1951) and several definitions can be found in the literature. According to Birkinshaw et al. (2008, p. 829), organizational innovation corresponds to "the generation and implementation of a management practice, process, structure, or technique that is new to the state of the art and is intended to further organizational goals". For Damanpour and Aravind (2011), the concept of organizational innovation is broadly similar to "management innovation" and it refers to new approaches in knowledge for performing the work of management and new processes that lead to changes in the firm strategy, structure, administrative procedures, and systems. 
For example, organization innovation can involve new methods for assigning responsibilities, which can improve employees' satisfaction, and in turn productivity, but it can also encompass new ways of organizing relations and collaborations with other organizations (Nieves, 2016).

The deployment of organizational innovation is routed on strategic reasons (OECD, 2005), and it has been acknowledged that the pursuit of organizational innovation aims to build or reinforce competitive advantage and economic performance (Som et al., 2012). There is also evidence that suggests that organizational innovation is usually carried out concurrently with technological innovation (e.g. Hollen et al., 2013). The literature provides evidence of the impact of organizational innovation on the competitive environment (e.g. Hamel, 2006; Chandler, 1962). As the competitive environment becomes increasingly complex and the pace of technology change accelerates, firms face the challenge to change organizational practices, processes and structures (Vacaro et al., 2012; Hecker and Ganter, 2013). Organizational innovation is a non-technology innovation, it deals with people (Lopez-Valeiros et al., 2016). Management innovations are often exclusive to the firms that adopt them, which avoids its replication (Vacaro et al., 2012; Damanpour and Gopalakrishnan, 2001); therefore, organizational innovation can provide and sustain competitive advantages (Hecker and Ganter, 2013; Mol and Birkinshaw, 2009). Management innovations relate to changes in what managers do and how they do it, that is organizational innovation is about how managers set directions, make decisions, coordinate activities, and motivate people (Hamel, 2006). This kind of innovations exhibit a high degree of idiosyncrasy and embeddedness in the organizational and social context of the implementing firm (Hecker and Ganter, 2013) and emerge without a dedicated infrastructure (e.g. research labs), which make them ambiguous and hard to imitate (Vacaro et al., 2012; Birkinshaw et al., 2008).

Organizational innovation can be a precondition for any other form of innovation (e.g. Lam, 2005). For example, Azar and Ciabuschi (2017) found evidence of the important role of organizational innovation as an antecedent condition of technological innovation in the context of exporting activities. Furthermore, recent research suggested that organizational innovation can be a necessary condition for certain complementarities (Guisado-González et al., 2017). According to socio-technical system theory, a change in a firm's technological system requires changes in the administrative system (Azar and Ciabuschi, 2017). Organizational innovations, such as structural improvements and organizational changes (e.g. policies, practices, and communication), can enhance intra- 
organization coordination and cooperation, which in turn can generate a favourable environment for adoption and utilization of technological innovations (Damanpour and Evan, 1984). For example, Gunday et al. (2011) found that structural improvements, which relate to organizational innovations (e.g. introducing a new human resources management system) have positively influenced the intra-organizational coordination and cooperation, which result in a better environment for the adoption of process innovation. Other authors also found evidence that organizational innovation can improve process innovation (e.g. Hervas-Oliver et al., 2014). Moreover, organizational innovation can contribute to the development of dynamic capabilities (Gebauer, 2011).

However, the literature suggests that organizational innovation needs the presence of other conditions to be effective. Prior research shows that organizational innovation impacts firms' performance through product innovation (Nieves, 2016), thereby implying that organizational innovation is not a sufficient condition to improve firms' performance. The results obtained by Nieves (2016) suggest that organizational innovation is an antecedent condition for product innovation, but it has also been noted that the mere implementation of organizational innovation is not enough to foster product innovation (e.g. Camisón and Villar-López, 2014). Thus, further research is needed to clarify the role of organizational innovation. Research on organizational innovation has been scarce within innovation literature (Crossan and Apaydin, 2010) and its implications remain rather unclear (Ganter and Hecker, 2014).

\subsubsection{Product and process innovation}

According to OECD (2005), process innovation corresponds to a new or significantly improved production or delivery method, which includes significant changes in techniques, equipment and/or software. Process innovation is associated to changes in a methodology or process that lead to higher efficiency, such as faster processing, greater throughput, or lower cost (Kahn, 2018). Product innovation refers to a good or service that is new or significantly improved. The latter involves significant improvements in technological specifications components and materials, software in the product, user friendliness or other functional characteristics.

Recent innovation literature has claimed that product and process innovation are different ways of contributing to firms' competitiveness that are usually interrelated (e.g. Hullova et al., 2016), but research that focus on these complementarities has been scarce and many times inconclusive. Product and process innovations present many differences, namely 
in terms of target, knowledge involved, and success measures. While product innovation targets external customers or users (Utterback and Abernathy, 1975), process innovation is mainly focused on the end-users within the organizations (Damanpour and Gopalakrishnan, 2001). Thus, compared to product innovation, process innovation does not require so much a market orientation (Stadler, 2011). Regarding the knowledge involved, product innovation is rather autonomous (Fang et al., 2010) and explicit, while process innovation is rather tacit (Gopalakrishnan et al., 1999). Furthermore, process innovation tends to be more systemic since it must be integrated with other firm specific resources (Damanpour and Gopalakrishman, 2001); process innovation has been linked to dynamic capabilities (Piening and Salge, 2015). Process innovation can contribute to enable economies of scale and reduce costs or to increase capacity and flexibility (Edquist, 2001; Simonetti et al., 1995). Thus, it can also be linked to manufacturing flexibility. In fact, process innovation relates to all operational activities performed to achieve competitive advantage (Lopez-Valeiras et al., 2016). However, unlike product innovation which is often linked with revenue generation, the success measure of process innovation tends to be efficiency enhancement (Utterback and Abernathy, 1975; Wong et al., 2008).

\subsection{Complementarities-in-performance and complementarities-in-use}

Since the seminal work of Schumpeter (1934), the literature has acknowledged the existence of complementarities among different forms of innovation. A stream of research has focused on the outcomes of the joint adoption of technological and organizational innovations (e.g. Ettlie and Reza, 1992). This approach was coined "complementarities research", but is still on its infancy, although it has received more attention lately (e.g. Hullova et al., 2016; Ballot et al., 2015; Ganter and Hecker, 2014; Brynjolfsson and Migrom, 2013; Sapprasert and Clausen, 2012; Ennen and Ritcher, 2010; Battisti and Stoneman, 2010). As aforementioned, the study of complementarities has followed two different main approaches: which were termed complementarities-in-performance and complementarities-in-use by Ballot et al. (2015). The former investigates the economic value of combining different activities and practices (e.g. Pisano and Wheelwright, 1995), while the latter investigates the linking between two sets of activities and suggests that one practice often requires other practice (e.g. Kurkkio et al., 2011).

The literature has established that organizational innovation is closely related with technological innovation (e.g. Battisti and Stoneman, 2010; Laursen and Foss, 2003), but this relationship remains unclear. Previous studies have shown a positive relation between 
organizational innovation and a firm's rate of product and process innovation (e.g. Laursen and Foss, 2003). However, the inverse relation can also occur: the implementation of product and process innovations can influence the development of organizational innovation (e.g. Ganter and Hecker, 2014). In fact, recent research has mainly addressed the effect of technological innovation (i.e., product and process innovation) on organizational innovation (e.g. Hervas-Oliver and Sempere-Rippol, 2015). This study addresses complementarities-inperformance from combining different forms of innovation, including both organizational and technological innovation.

The conditional tests conducted by Ballot et al. (2015), using French and UK data from the Community Innovation Survey (CIS), suggested that the combination of product and process innovation, or the joint development of organizational and product innovation, can result in higher performance, but firms have no advantage from combining all three forms of innovation. Since the results of the unconditional tests were inconclusive, these authors tested pairwise relations that were conditional on the presence/absence of the third form. Their results suggested that complementarities between product and process innovation occur only if organizational innovation is absent. However, this result is not consistent with previous literature (e.g. Lam, 2005; Laursen and Foss, 2003). Ballot et al. (2015) also found a substitution effect between process innovation and organizational innovation, if the product innovation is present. Regarding the combination of product and organizational innovation, when process innovation is absent, their results are mixed: they found no relation between product and organizational innovation using the UK data, but for French firms, they found that product innovation and organizational innovation are conditional complements, if process innovation is absent. The results obtained by Ballot et al. (2015) have some limitations, since they do not hold in unconditional testing and some measures (for instance, regarding organizational innovation and firm performance) may lack important elements; however, considering complementarities-in-performance, they suggest the introduction of all three forms of innovation has no positive effect.

The innovation literature suggests that growth is linked with product development (e.g. Stam and Wennberg, 2009). Therefore, considering the importance of product innovation to enhance firms' revenue, this paper also analyses complementarities-in-use for product innovation. Besides process and organizational innovations, another antecedent condition was also considered: manufacturing flexibility. The latter involves restructuring manufacturing resources timely and efficiently through the development of multifunctional resources and coordination processes that facilitate the recombination of resources and 
synergy creation (Seebacher and Winkler, 2014). With the emergence of a "new industrial revolution", also called Industry 4.0, which combines advanced manufacturing techniques with information technology, business models of manufacturing firms are changing (Wei et al., 2017). These new business models require manufacturing flexibility, which has been acknowledged as a dynamic capability that supports the realignment and restructuring of resources in a dynamic environment (e.g. Anand and Ward, 2004). There is not a clear and consensual conceptualization of manufacturing flexibility (Pérez-Pérez et al., 2018), but it has been acknowledged as a key driver of firms' competitiveness (e.g. Yu et al., 2015). In fact, the importance of flexibility for innovation has been recognized long ago (e.g. Bolwijn and Kumpe, 1990) and the concept of manufacturing flexibility has become a key competitive criterion for many manufacturing firms (Oke, 2013). Moreover, successful innovation depends on a flexible, open culture, with low levels of bureaucracy (McAdam et al., 2004).

Manufacturing flexibility enables firms to reduce internal resource constrains that block the adoption of novelty-centred business models (Wei et al., 2017). Novelty-centred business models focus on the creation or capture of new opportunities, which result in new value propositions. New value propositions require firms to recombine resource portfolios, but inertia often obstructs this transformation (Gilbert, 2005). Manufacturing flexibility can reduce this inertia, thus promoting novelty-centred business models, and subsequently firm performance (Wei et al., 2017). Therefore, manufacturing flexibility can be extremely important to achieve high product innovation. Nevertheless, previous research noted that manufacturing flexibility alone is not enough to achieve high product innovation (Camisón and López, 2010).

Past research identified the climate for innovation (i.e. an environment or culture that encourages creativity and innovation through positive recognition, support and rewards systems) as a condition under which manufacturing flexibility will positively influence product innovation (Oke, 2013). The climate for innovation reflects the way the organization runs itself. Thus, it can be associated with organizational innovation. Oke (2013) suggests that in a high innovative climate, different creative ideas are more likely to result into product innovation if the firm has manufacturing flexibility. Furthermore, manufacturing flexibility is often linked with process innovation (e.g. Hervas-Oliver et al., 2014), and most research assumes that process innovation supports product innovation (e.g. Benner and Tushman, 2003). 
While some authors claimed that the synchronous adoption of product and process innovation is the "single best complementary strategy" (e.g. Damanpour, 2010), others suggested that there is no "winning strategy" to develop complementarities between these two forms of innovation (e.g. Hullova et al., 2016). The synergistic effects of combining product and process innovation have been claimed by the complementarities-in-performance research stream (e.g. Pisano and Wheelwright, 1995). However, taking the perspective of complementarities-in-use, some literature proposes a sequential model that implies only oneway relationship (Damanpour and Gopalakrishnan, 2001), suggesting that product innovation creates a need for process innovation. Because product innovations can be easier protected (e.g. by patents), some authors advocate that firms should first start with product innovation, followed by process innovations (e.g. Kraft, 1990).

The literature review presented herein, suggests multiple causal relations and calls for a further integration of organizational and technological innovation. Therefore, further research of the complex interplay among different forms of innovation is in order, and a configurational approach fits the purpose.

\subsection{The configurational approach}

While regression-based methods are based on the principle of symmetry, that is, higher values of an independent variable will either increase or decrease the outcome of interest, the configurational methods are based on the principle that the combination of conditions (i.e., configurations) are what matter. For this purpose, the use of fuzzy-set Qualitative Comparative Analysis (fsQCA), a technique that belongs to a general approach termed Qualitative Comparative Analysis (QCA) (Rihoux et al., 2011), has seen a rapid growth in recent years (see, for example, Berger 2016). Other methods, which have been widely used, such as linear regression models, clustering analysis, latent class analysis, or deviation score approach have notable limitations with complex, high-order interactions (Frösén et al., 2016). By exploring set relations, QCA techniques help to build and elaborate theory regarding whether a condition is necessary and/or sufficient for an outcome of interest to occur (McKnight and Ziestma, 2018). QCA examines the relationships between the outcome and all possible combinations of the binary states (i.e., presence or absence) of its predictors, performing a systematic cross-case analysis, thereby enabling the identification of configurations that reflect the necessary and sufficient conditions to achieve an outcome of interest (Ordanini et al., 2014). Moreover, this approach takes in consideration that some 
cases may contradict the main effect, that is, possible asymmetric effects are taking into account.

Although fsQCA is uniquely suitable for innovation research, its use has been scarce, with a few exceptions (e.g. Ganter and Hecker, 2014). The study conducted by Ganter and Hecker (2014) uses fsQCA to investigate the influence of technological innovation on organizational innovation. However, the solution cover of the identified configurations is only $22 \%$, which reflects a low empirical coverage. Nevertheless, their study highlights the usefulness of using fsQCA. These Authors claim that their study is just a first step and present avenues for future research that include the relationship of organizational research with other forms of innovation in building configurations of outstanding firm performance, which is the main focus of the present paper.

Considering the literature review, several tenets are proposed to guide this research. In configurational analysis, "tenet" is the term used for expressing testable precepts. As aforementioned the presence of complementarities-in-use does not necessarily imply the existence of complementarities-in-performance. The main objective of this study is to find necessary and sufficient conditions for high performance, considering different forms of innovation. To obtain clear readings, the study focuses on complementarities among product innovation, process innovation, and organizational innovation.

The results obtained by Hervas-Oliver and Sempere-Rippol (2015) indicate that focusing solely on either technological innovation or organizational innovation leads to a low-level of organizational performance. The study conducted by Ballot et al. (2015) also suggested that introducing all three forms of innovation has less effect on performance than developing two forms innovation, while introducing only organizational innovation has the lowest effect. Furthermore, some literature indicates that organizational innovation should be carried out with technological efforts (e.g. Hollen et al., 2013; Hervas-Oliver and Sempere-Rippol, 2015). The enhancement of firm performance results, not only from developing resources, but also from the capability to integrate them in a unique way (Ennen and Ritcher, 2010); the entire system complexity prevents imitation (Rivkin, 2000) and promotes sustainable competitive advantage (Dierickx and Cool, 1989).

While some authors argued that the best solution to enhance organizational returns would be the combination of process innovation with organizational innovation, suggesting that product innovation and organizational innovation should not be introduced at the same time (e.g. Hervas-Oliver and Sempere-Rippol, 2015); others found that introducing product and organizational innovation can be beneficial (e.g. Ballot et al., 2015). Therefore, in the 
present study both combinations are asserted to be possible solutions for firm performance enhancement. However, unlike the study of Ballot et al. (2015), which use conditional testing, the present analysis uses unconditional testing, that is, a solution that combines of two antecedent conditions does not require necessarily the presence/absent of a third condition. Therefore, to guide this research, the following tenets were formulated, expressed in terms of necessity and sufficiency, regarding complementarities-in-performance:

T1.1. The presence or the absence of a simple antecedent condition (product innovation, process innovation, and organizational innovation) is neither necessary nor sufficient to obtain the outcome condition (performance).

T1.2. A combination of organizational innovation with one form of technological innovation (product or process innovation) can be sufficient to achieve high levels of performance.

T1.3. Combinations of antecedent conditions that lead to low performance, are not necessarily the mirror opposites of complex conditions (i.e., configurations), leading to high performance.

In the same vein, regarding complementarities-in-use for high product innovation, three tenets are proposed considering the following antecedent conditions: organizational innovation, process innovation, and manufacturing flexibility. In line with previous research (e.g. Wei et al., 2017), manufacturing flexibility is considered an important condition for product innovation. However, inspired on the study conduct by Camisón and López (2010), it is also asserted that only manufacturing flexibility alone may not be sufficient to achieve high levels of product innovation. Furthermore, the literature review suggests that manufacturing flexibility can be linked with organizational innovation and/or process innovation. Inspired on the results obtained by Ballot et al. (2015), it is also assumed that the presence of two antecedent conditions can be sufficient to achieve the outcome of interest (i.e., product innovation). As noted by Laforet (2011) the literature has ignored the negative outcomes of innovation, with a few exceptions. Simpson et al. (2006) suggests that the negative consequences include, for example, unnecessary risks, enabling followers to copy an idea, and also contributes to negative employee attitudes that may lead to job stress, and dissatisfaction. Therefore, it is relevant to study the conditions that lead to low product innovation Thus, because of non-linearity hypothesis that is introduced in this study, the configurations that lead to low and high product innovation are not necessarily symmetrical. Therefore, the following tenets were formulated. 
T2.1. The presence or the absence of a simple antecedent condition (organizational innovation, process innovation, and manufacturing flexibility) is neither necessary nor sufficient to obtain the outcome condition (product innovation).

T2.2. A combination of manufacturing flexibility with either organizational or process innovation can be sufficient to achieve high levels of product innovation.

T2.3. Combinations of antecedent conditions that lead to low product innovation, are not necessarily the mirror opposites of complex conditions (i.e., configurations) leading to high product innovation.

\section{Research design}

\subsection{Data and measures}

Different from previous research that used data from CIS (e.g. Ballot et al., 2015; HervasOliver and Sempere-Rippol, 2015), this study uses data from 223 unlisted Portuguese industrial firms, which was obtained after sending 2120 surveys by email to a database provide by Compagnie Française d'Assurance pour le Commerce Extérieur (COFACE), corresponding to a response rate of $10.52 \%$. To assess the non-response bias the means for each scale item for the first fifty answers were compared with the same means of the last fifty answers, as recommend by Armstrong and Overton (1977), using a $t$-test for the equality of means. The $t$-test results show no significant differences between the means of the two groups of the 35 items used to measure the model variables, with two exceptions, at the conventional significance level (5\%). Thus, the non-response bias is not a major concern in the present study.

The data collected from CIS presents several limitations; therefore, using different sources of data has been recommended. Moreover, it has been suggested that future research should consider different performance measurements (e.g. Ballot et al., 2015). This survey responds to this call by using different measures and collecting data from industrial firms located in Portugal (most of previous studies focused on countries like France, Germany, Spain, and UK). The measures for product innovation (PROD), process innovation (PROC), organizational innovation (ORG), and manufacturing flexibility (FLEX) were adapted from Camisón and López (2010). These authors used in great extent the Olso Manual (OECD, 2005) to generate the scales. Organizational performance (PERF) was assessed considering several elements, including the market share growth, customers' satisfaction, customers' retention, productivity, return on assets, and mean sales profitability; the scale was adapted 
from Nahm et al. (2003) and Camisón and López (2010). The survey was pre-tested using a sample of five top managers of Portuguese manufacturing firms, in order to assess its practical relevance and face validity. After the pre-test, the measurement instrument was modified and improved. The items used to measure each construct are presented in Table 1, which also presents the Cronbach's alpha values.

\section{(Insert Table 1 about here)}

As aforementioned the data collection used relied on self-administered online survey, therefore common method variance (CMV) can occur (Fuller et al., 2016). This potential bias arises when the variance of the answers is more attributable to the single measurement used than to the variables that those measures represent (Podsakoff et al., 2003). To attend for this potential bias both ex-ante and ex-post control procedures were employed. Following Podsakoff et al. (2003), ex-ante several control procedures were adopted. The survey was pre-tested using a pilot study with five general manager/chief executive officers of the Portuguese manufacturing firms to access the comprehensibility of the scale used, its practical relevance, define ambiguous terms, avoid vague concepts and complex syntax, and keep each question simple, specific and concise. In the first page of the survey and in the cover letter, we addressing the nature of the study and ensuring the confidentiality of the answers.

Ex-post the common method bias can be tested using different techniques (e.g. Harman's single factor test, confirmatory factor analysis (CFA) test, correlational marker technique, single unmeasured latent method factor, and multiple method factors). In this study, we used the Harman's single-factor test (the most frequently used according to Fuller et al., 2016) and, following Baldauf et al. (2009) and So et al. (2013), the CFA test. According the Harman's single-factor test, CMV is problematic if an exploratory factor analysis with all variables show that first factor extracted (without rotation) accounts more than $50 \%$ of the variance of the original variables (Podsakoff and Organ, 1986). In our case, six factors with eigenvalues greater than one, and the proportion of variance explained by each factor was as follows: 41.7, 8.7, 6.7, 6.3, 3.3, and 3.1. Using the CFA test with all 35 items loaded on a single common factor, and applying a chi-square difference test, the common factor model $\left(\chi^{2}=2,856.2, d f=560\right)$, was compared to CFA results of the proposed measurement model with five constructs $\left(\chi^{2}=1,578.4, d f=550\right)$. The results of the chisquare difference test show that the model with five constructs fits better than common factor 
model $\left(\Delta \chi^{2}=1,277.8, d f=10, p<.01\right)$. Thus, both ex ante and ex post procedures used suggested that the CMV is not a major issue in this study.

\subsection{Method}

This research employs fsQCA to identify configurations of conditions that support high performance and high product innovation; low-levels (absence) of these outcomes were also analysed. Following Schneider et al. (2010), the fsQCA technique is suitable for the study of complementarities and non-linear relationships among constructs because: i) asymmetrical causality is allowed, ii) combinations of antecedent conditions, rather than single conditions, are considered to be linked to the outcome, iii) the idea of equifinality is captured, that is, multiple causal paths may result into the same outcome, and $i v$ ) links between the various combinations of causal conditions and the outcome are expressed as necessary and sufficient conditions. fsQCA is uniquely suitable for innovation research, considering the complex patterns and causal interrelations among the conditions that contribute for innovation activity and success (Ganter and Hecker, 2014). Even more so for complementarities research because non-linear relationships are the heart of the complementarity concept (Ballot et al., 2015). Thus, fsQCA is can be an adequate method to identify complementarities in configurations (Fiss, 2011).

The fsQCA requires the specification of full membership and full non-membership thresholds, and a cross-over point of maximum ambiguity. The transformation of original data into a scale over the interval $[0,1]$ is termed "calibration"; this procedure preserves information by allowing gradual set membership. Each threshold translates into a specific fuzzy value - it is standard to use fuzzy values of $.95, .05$, and .50 for the full membership and non-membership thresholds, and for the cross-over point, respectively (see Ragin, 2008). Following prior research (e.g. Torres and Augusto, 2019; Ho et al., 2016), the thresholds for full membership, non-membership thresholds, and for the cross-over point, were defined using the $90^{\text {th }}, 10^{\text {th }}$, and $50^{\text {th }}$ percentiles of the values of the original distribution of each condition.

After computing original values of the conditions into fuzzy scores, an analysis of necessary conditions should be performed (Schneider and Wagemann, 2010). The evaluation of necessary conditions should consider the consistency and trivialness of necessity (Ragin, 2008). Following previous research (e.g. Torres and Augusto, 2019; Schneider et al., 2010), a consistency threshold of .90 was considered adequate for the analysis of necessary conditions. The conditions are considered not trivial, if they show a non-negligible coverage. 
Regarding the configurational analysis, values less than .75 for the consistency threshold should be avoided, and using values of .80 or higher have been recommend (see Ragin, 2009).

\section{Results}

The analysis of necessary conditions for high and low levels of performance is presented on Table 2. The tilde “ " represents negation (i.e., absence). As expected, the presence of the antecedent conditions is relatively more important than its absence, when trying to achieve high performance. The absence of the antecedent conditions tends to be more meaningful in explaining low performance. Nevertheless, per se, none of the antecedent conditions (i.e., ORG, PROD, and PROC) can be considered necessary, since all the values are below the .90 threshold.

(Insert Table 2 about here)

The results of the configurational analysis presented in Table 3 show that high performance occurs when both PROD and ORG are present; PROC is not part of the solution, indicating that it could be either present or absence. The obtained configuration (PERF1) has acceptable consistency ( $\mathrm{C} 1=.857$, above the .80 threshold) and empirical coverage $(\mathrm{C} 2=.617)$. Regarding low performance $(\sim \mathrm{PERF})$, three solutions were obtained [all solutions present acceptable consistency $(\geq .80)$ and raw coverage (>.30)]. These solutions result from the joint absence of any two of the three antecedent conditions. The configuration $\sim$ PERF1 ( PROC* $\sim$ ORG) has the highest unique coverage, followed by $\sim$ PERF3 ( PROD* $\sim$ PROC). The unique coverage of $\sim$ PERF1 and $\sim$ PERF3 (C3=.087 and $\mathrm{C} 3=.077$, respectively) is significantly above $\sim$ PERF2 $(\mathrm{C} 3=.044)$, which means that the first two configurations $(\sim \mathrm{PROC} * \sim \mathrm{ORG})$ or $(\sim \mathrm{PROD} * \sim \mathrm{PROC})$ are relatively more important in explaining the lack of performance than the latter $(\sim \mathrm{PROD} * \sim \mathrm{ORG})$. This result is interesting because $\sim$ PERF1 and $\sim$ PERF3 are not the mirror opposites of the configuration leading to high performance (PERF1).

(Insert Table 3 about here)

In synthesis, the results indicate that no antecedent condition alone is neither necessary nor sufficient to achieve high performance (confirming the tenet T1.1) and they 
also show that the integration of technological innovation with organizational innovation is needed (which confirms the tenet T1.2). However, different from past research, the results suggest that the best way to enhance performance is combining product and organizational innovation. The results also show that the absence of two of the three forms of innovation considered in this study leads to low performance. Furthermore, they indicate that there are multiple paths that lead to low performance (confirming the tenet T1.3). Finally, the results demonstrate the usefulness of using fsQCA in complementarities research.

Table 4 presents the analysis of necessary conditions for high and low product innovation. Again, no single condition is necessary for these outcomes. All the consistency values are below the .90 threshold. This analysis was performed separately from the analysis of sufficiency as recommended by Ragin (2008) to avoid mistakenly interpreting a condition that is present in every sufficient configuration as a necessary condition.

(Insert Table 4 about here)

The results of the configurational analysis indicate that high product innovation (i.e., PROD) occurs when FLEX is combined with either PROC or ORG (see Table 5). Both solutions present high consistency values, .893 and .879, and raw coverages, .651 and .600, respectively. The combined models account more than $70 \%$ of membership in this outcome (overall $\mathrm{C} 2=.703$ ). The first configuration, PROD1 (FLEX*PROC), has a higher unique coverage $(\mathrm{C} 3=.103)$ and raw coverage $(\mathrm{C} 2=.651)$ indicating that it is the most relevant. Furthermore, the absence of these conditions leads to $\sim$ PROD, reinforces the importance of combining FLEX and PROC to achieve high levels of product innovation. FLEX is the most frequent condition in the models leading to PROD, it is present in both solutions leading to PROD, which also has qualitative significance.

\section{(Insert Table 5 about here)}

In summary, the presence/absence of a simple antecedent condition (ORG, PROC, or FLEX) is neither necessary nor sufficient to obtain high levels of PROD (confirming the tenet T2.1.). The joint presence of FLEX with either ORG or PROC can be sufficient to achieve high levels of product innovation (which confirms the tenet T2.2.). Furthermore, while there are two configurations that lead to PROD, only one solution was obtained for 
$\sim$ PROD, which indicates that configurations that lead to $\sim$ PROD, are not necessarily the mirror opposites of configurations leading to PROD (confirming the tenet T2.3.).

A synthesis of the obtained results for high and low performance and high and low product innovation is presented in Table 6. All tenets were supported.

(Insert Table 6 about here)

\section{Discussion and conclusions}

\subsection{Discussion}

The literature has widely acknowledged that innovation drives firm performance (e.g. Jong, 2013, Visnjic et al., 2016). However, firms must combine different types of innovation to achieve high performance. This paper highlights that using a configurational approach, namely fsQCA, in complementarities research is a suitable method, and contributes to innovation literature in several ways.

First, this study contributes to understanding complementarities-in-performance among the three forms of innovation and identifies a "winning strategy": the combination of organizational innovation with product innovation. In line with Evangelista and Vezzani (2010), but in contrast with the results obtained by Nguyen-Thi and Mothe (2010), organizational innovation plays a crucial role in enhancing firm performance. The "winning strategy" is consistent with the literature that recognized the advantages of combining technological and organizational innovation, which called for the integration of organizational and technological innovation (e.g. Hollen et al., 2013; Battisti and Stoneman, 2010). But, unlike past research (e.g. Ballot et al., 2015), the results show that process innovation is indifferent to achieve high performance. While the joint presence of organizational and product innovation is sufficient to obtain high performance, process innovation could be either present or absent (its absence is not required). This result shows that it is not necessary to invest in all three forms of innovation to achieve competitive advantage through innovation, in contrast with what has been suggested by some authors (e.g. Evangelista and Vezzani, 2010).

Organizational innovation should be combined with product innovation, which is coherent with Nguyen-Thi and Mothe (2010) argument that organizational innovation leads to a higher propensity to introduce new or improved products. This finding is consistent with prior studies which suggested that the adoption of a single type of innovation would not 
enable firms to take full advantage of the benefits of innovation (e.g. Damanpour and Arayind, 2011). The obtained results support the idea that organizational changes are a complement to the improvement of performance of firms' products, as suggested by Evangelista and Vezzani (2010). This implies that organizational innovation can help the organization to create and sustain competitive advantages (Hecker and Ganter, 2013; Mol and Birkinshaw, 2009); but product innovation is also required to achieve high levels of performance.

Second, this study identifies configurations that lead to low performance and the results suggest that the absence of two conditions (out of the three that were considered in the analysis) can result in this outcome. Two of the obtained configurations are not the mirror opposites of the results obtained for high performance. This finding justifies the adoption of non-linear methodologies when studying complementarities.

Third, regarding complementarities-in-use for product innovation, the importance of manufacturing flexibility is highlighted, since it is present in both solutions leading to high levels of product innovation. As aforementioned in the analysis of necessary conditions, when a condition is present in every configuration that does not indicate that the condition is necessary (Ragin, 2008). The analysis of necessary conditions shows that none of the antecedent conditions is necessary. However, high levels of product innovation can be achieved through the joint presence of manufacturing flexibility with either process innovation or organization innovation. Since there is a solution that does not include process innovation, it means that process innovation is not always required to achieve high levels of product innovation, which is contrary to some past studies (e.g. Benner and Tushman, 2003; Damanpour and Gopalakrishnan, 2001). Nevertheless, it also shows that the combination of process innovation with manufacturing flexibility often occurs, as claimed in previous research (e.g. Hervas-Oliver et al., 2014).

The importance of manufacturing flexibility to firms' competitiveness has been noted in the literature (e.g. Yu et al., 2015; Oke, 2013; Bolwijn and Kumpe, 1990). Process innovation relates to dynamic capabilities (Piening and Salge, 2015) and it can contribute to enhance flexibility (Edquist, 2001; Simonetti et al., 1995). Therefore, the joint presence of manufacturing flexibility with process innovation to achieve high levels of product innovation is understandable. The literature noted that process innovation supports product innovation (e.g. Benner and Tushman, 2003) and pointed out that these two types of innovation are often interrelated (e.g. Hullova et al., 2016). The results obtained in the 
present study support this view, but suggest that process innovation should be combined with manufacturing flexibility to achieve high levels of product innovation.

Prior research also suggested that the climate for innovation can be a condition under which manufacturing flexibility will positively influence product innovation (Oke, 2013). The climate for innovation reflects the way the organization runs itself. Thus, management innovations can be relevant because they relate to changes in what managers do and how they do it (Hamel, 2006). The results indicate that organizational innovation can be an antecedent condition for technological innovation, as suggested by some authors (e.g. Le Bas et al., 2015; Armbruster et al., 2008; Lam, 2005). Furthermore, it further corroborates the idea that successful implementation of technological innovations requires an appropriate administrative component of the organization, that is the firm should be open to new ideas and practices (Azar and Ciabuschi, 2017). Organizational innovation can create an appropriate environment for enhancing flexibility and creativity, which in turn can facilitate the development of product innovation. This result supports the idea that organizational innovation can be linked to product innovation (e.g. Wong, 2013; Laursen and Foss, 2003). Moreover, organizational innovation can contribute to the development of dynamic capabilities (Gebauer, 2011) and manufacturing flexibility has been acknowledged as a dynamic capability (Anand and Ward, 2004). Therefore, the complementarity between organizational innovation and with manufacturing flexibility to obtain high levels of product innovation is also understandable.

\subsection{Practical implications}

The results discussed in the previous subsection also have important practical implications. Firms should promote both organizational innovation and product innovation to achieve high levels of performance, but they should also be aware of the complementarities-in-use for product innovation. In fact, considering the importance of developing product innovation to enhance performance, firms should try to achieve high levels of product innovation. To achieve this outcome, manufacturing flexibility should be present. Managers are highly encouraged to invest in manufacturing flexibility in order to facilitate the development of product innovation.

The findings suggest that organizational innovation plays an important role. Hence, managers are advised to implement innovations in the management practices, processes, and structures. Organizational innovation should be combined with product innovation to achieve high levels of performance. Organizational innovation is about how managers run 
their firms (set directions, make decisions, coordinate activities, and motivate people), presents a high degree of idiosyncrasy and do not require a dedicated infrastructure. Thus, because it is ambiguous and hard to replicate, organizational innovation can contribute to the generation and sustainability of competitive advantages.

Furthermore, management innovations can lead to a highly innovative climate, in which different creative ideas are more likely to result into product innovation and the findings suggest that manufacturing flexibility should be also present to achieve high levels of product innovation. The results also show that high levels of product innovation can also be obtained with the joint presence of manufacturing flexibility and process innovation. Therefore, when aiming to improve product innovation, managers can follow one the two strategies presented herein.

\subsection{Limitations and future research}

As in every research, this study is not without limitations. The empirical evidence reported in this paper may be influenced by the definitions that were considered. Further conceptual and empirical research is encouraged to corroborate, consolidate (or refute) the findings presented herein. Moreover, although the results obtained in this research present a high empirical coverage, other antecedent conditions beyond the scope of this study can also play an important role; for instance, marketing could influence innovation performance.

Furthermore, this study used a sample of manufacturing firms. Previous research has shown that differences between manufacturing and service firms are not significant (e.g. Evangelista and Vezzani, 2010). However, supplementary research could examine if service companies require different configurations of innovation forms. Moreover, radical innovation was not distinguished from incremental innovation when analyzing firm performance. Finally, the study relies on primary data, which may have biased the results. Future research can address these shortcomings, including different conditions, using different databases and methodologies, in order to improve the understanding of how innovation works. 


\section{References}

Anand, L.S. and Ward, P.T. (2004). "Fit, flexibility and in manufacturing: coping with dynamic environments", Production and Operations Management, Vol. 13 No. 4, pp. 369-385.

Armbruster, H., Bikfalvi, A., Kinkel, S. and Lay, G. (2008), "Organizational innovation: The challenge of measuring non-technical innovation in large-scale surveys", Technovation, Vol. 28 No. 10, pp. 644-657.

Armstrong, J. S. and Overton, T. S. (1977), "Estimating nonresponse bias in mail surveys", Journal of Marketing Research, Vol. 14 No. 3, pp. 396-402.

Azar, G. and Ciabuschi, F. (2017), "Organizational innovation, technological innovation, and export performance: The effects of innovation radicalness and extensiveness", International Business Review, Vol. 26 No. 2, pp. 324-336.

Baldauf, A., Cravens, K.S., Diamantopoulos, A. and Zeugner-Roth, K.P. (2009), “The impact of product-country image and marketing efforts on retailer-perceived brand equity: An empirical analysis", Journal of Retailing, Vol. 85 No. 4, pp. 437-452.

Ballot, G., Fakhfakh, F., Galia, F. and Salter, A. (2015), "The fateful triangle: Complementarities in performance between product, process and organizational in France and UK", Research Policy, Vol. 44 No. 1, pp. 217-232.

Battisti, G. and Stoneman, P. (2010), "How innovative are UK firms? Evidence from the fourth UK community innovation survey on synergies between technological and organizational innovations", British Journal of Management, Vol. 21 No. 1, pp. 187-206.

Benner, M. and Tushman, M. (2003), "Exploitation, exploration, and process management: The productivity dilemma revisited", Academy of Management Review, Vol. 28 No. 3, pp. 238-256.

Berger, E.S. (2016), "Is qualitative comparative analysis an emerging method?Structured literature review and bibliometric analysis of QCA applications in business and management research", in: E.S.C. Berger and Kuckertz (Eds.), Complexity in entrepreneurship, innovation and technology research, applications of emergent and neglected methods, Springer International Publishing, Basel, pp. 287-308

Birkinshaw, J., Hamel, G. and Mol, M. (2008), "Management innovation", Academy of Management Review, Vol. 33 No. 4, pp. 825-845.

Bolwijn, P.T. and Kumpe, T. (1990), "Manufacturing in the 1990s - productivity, flexibility and innovation”, Long Range Planning, Vol. 23 No. 4, pp. 44-57.

Bos-Brouwers, H.E.J. (2010), "Corporate sustainability and innovation in SMEs: evidence of themes and activities in practice", Business Strategy and the Environment, Vol. 19 No. 7, pp. 417-435.

Brynjolfsson, E. and Milgrom, P. (2013), "Complementarity in organizations", in Gibbons, R.R. and Roberts, J. (Eds.), The Handbook of Organizational Economics. Princeton University Press, Princeton, NJ. 
Camisón, C. and López, A.V. (2010), "An examination of the relationship between manufacturing flexibility and firm performance", International Journal of Operations \& Production Management, Vol. 30 No. 8, pp. 853-878.

Camisón, C. and Villar-López, A. (2014), "Organizational innovation as an enabler of technological innovation capabilities and firm performance", Journal of Business Research, Vol. 67 No. 1, pp. 2891-2902.

Chandler, A.D. (1962), Strategy and structure: Chapters in the history of the American industrial enterprise, MIT Press, Cambridge, MA.

Cozzarin, B.P. (2017), "Impact of organizational innovation on product and process innovation", Economics of Innovation and New Technology, Vol. 26 No. 5, pp. 405-417

Crossan, M.M. and Apaydin, M. (2010), "A multi-dimensional framework of organizational innovation: A systematic review of the literature", Journal of Management Studies, Vol. 47 No. 6, pp. 1154-1191.

Damanpour, F. (2010), “An integration of research findings of effects of firm size and market competition on product and process innovations", British Journal of Management, Vol. 21 No. 4, pp. 996-1010.

Damanpour, F. and Aravind, D. (2011), "Managerial innovation: Conceptions, processes, and antecedents", Management and Organization Review, Vol. 8 No. 2, pp. 423454

Damanpour, F. and Evan, W.M. (1984), "Organizational innovation and performance: The problem of organizational lag”, Administrative Science Quarterly, Vol. 29 No. 3, pp. 392- 409 .

Damanpour, F. and Gopalakrishnan, S. (2001), "The dynamics of the adoption of product and process innovation in organizations", Journal of Management Studies, Vol. 38 No. 1, pp. 45-65.

Dean, J.W. Jr and Snell, S.A. (1996), "The strategic use of integrated manufacturing: An empirical examination", Strategic Management Journal, Vol. 17 No. 6, pp. 459480.

Dierickx, I. and Cool, K. (1989), "Asset stock accumulation and sustainability of competitive advantage”, Management Science, Vol. 35 No. 12, pp. 1504-1511.

Doran, J. (2012), “Are differing forms of innovation complements or substitutes?", European Journal of Innovation Management, Vol. 15 No. 3, pp. 351-371.

Edquist, C. (2001), "Innovation policy: a systemic approach", Oxford University Press, Oxford.

Ennen, E. and Richter, A. (2010), "The whole is more than the sum of its parts - or is it? A review of the empirical literature on complementarities in organizations", Journal of Management, Vol. 36 No. 1, pp. 207-233.

Ettlie, J.E. and Reza, E.M. (1992), “Organizational integration and process innovation”, Academy of Management Journal, Vol. 35 No. 4, pp. 795-827.

Evangelista, R. and Vezzani, A. (2010), "The economic impact of technological and organizational innovations. A firm-level analysis", Research Policy, Vol. 39 No. 10, pp. 1253-1263. 
Fang, C., Lee, J. and Schilling, M.A. (2010), "Balancing exploration and exploitation through structural design: The isolation subgroups and organizational learning", Organization Science, Vol. 21 No. 3, pp. 625-642.

Fiss, P.C. (2011), "Building better causal theories: A fuzzy set approach to typologies in organization research", Academy of Management Journal, Vol. 54 No. 2, No. 393420.

Fritsch, M. and Meschede, M. (2001), "Product innovation, process innovation, and size", Review of Industrial Organization, Vol. 19 No. 3, pp. 335-350.

Frösén, J., Luoma, J., Jaakkola, M., Tikkanen, H. and Aspara, J. (2016), "What counts versus what can be counted: The complex interplay of market orientation and marketing performance measurement", Journal of Marketing, Vol. 80 No. 3, pp. 60-78.

Fuller, C.M., Simmering, M.J., Atinc, G., Atinc, Y. and Babin, B.J. (2016), “Common methods variance detection in business research", Journal of Business Research, Vol. 69, pp. 3192-3198.

Ganter, A. and Hecker, A. (2014), "Configurational paths to organizational innovation: qualitative comparative analysis of antecedents and contingencies", Journal of Business Research, Vol. 67 No. 2, pp. 1285-1292.

Gebauer, H. (2011), "Exploring the contribution of management innovation to the evolution of dynamic capabilities", Industrial Marketing Management, Vol. 40 No. 8, pp. 1238-1250.

Gilbert, C. (2005), "Unbundling the structure of inertia resource versus routine rigidity", The Academy of Management Journal, Vol. 48 No. 5, pp. 741-763.

Gopalakrishnan, S., Bierly, P. and Kessler, E.H. (1999), "A re-examination of product and process innovations using a knowledge-based view”, The Journal of High Technology Management Research, Vol. 10 No. 1, pp. 147-166.

Guisado-González, M., Wright, L.T. and Guisado-Tato, M. (2017), "Product-process matrix and complementarity approach", The Journal of Technology Transfer, Vol. 42 No. 3, pp. 441-459.

Gunday, G., Ulusoy, G., Kilic, K. and Alpkan, L. (2011), "Effects of innovation types on firm performance", International Journal of Production Economics, Vol. 133 No. 2, pp. 662-676.

Hamel, G. (2006), "The why, what, and how of management innovation", Harvard Business Review, Vol. 84 No. 2, pp. 72-84.

Hayes, R.H. and Wheelwright, S.C. (1979a), "Link manufacturing process and product life cycles", Harvard Business Review, Vol. 57 No. 1, pp. 133-140.

Hayes, R.H. and Wheelwright, S.C. (1979b), "The dynamics of process-product life cycles", Harvard Business Review, Vol. 57 No. 2, pp. 127-136.

Hecker, A. and A. Ganter (2013), "The influence of product market competition on technological and management innovation: Firm-level evidence from a large-scale survey”, European Management Review, Vol. 10 No. 1, pp. 17-33. 
Hervas-Oliver, J-L. and Sempere-Rippol, F. (2015), "Disentangling the influence of technological process and product innovations", Journal of Business Research, Vol. 68 No. 1, pp. 109-118.

Hervas-Oliver, J-L., Sempere-Rippol, F.and Boronat-Moll, C. (2014), "Process innovation strategy in SMEs, organizational innovation and performance: A misleading debate?", Small Business Economics, Vol. 43 No. 4, pp. 873-886.

Ho, J., Plewa, C. and Lu, V.N. (2016), "Examining strategic orientation complementarity using multiple regression analysis and fuzzy set QCA", Journal of Business Research, Vol. 69 No. 6, pp. 2199-2205.

Hollen, R., Den Bosch, Van, Frans, A.J. and Volberda, H.W. (2013), "The role of management innovation in enabling technological process innovation: An interorganizational perspective", European Management Review, Vol. 10 No. 1, pp. $35-50$.

Hullova, D., Simms, C.D., Trott, P. and Laczko, P. (2019), "Critical capabilities for effective management of complementarity between product and process innovation: Cases from the food and drink industry", Research Policy, Vol. 48 No. 1, pp. 339-354.

Hullova, D., Trott, P. and Simms, C.D. (2016), "Uncovering the reciprocal complementarity between product and process innovation", Research Policy, Vol. 45 No. 5, pp. 929-940.

Jong, J.P.J. (2013), “The decision to exploit opportunities for innovation: A study of hightech small-business owners", Entrepreneurship Theory and Practice, Vol. 37 No. 2, pp. 281-301.

Kahn, K.B. (2018), “Understanding innovation”, Business Horizons, Vol. 61 No. 3, pp. 453-460.

Kraft, K. (1990), “Are product - and process - innovations independent of each other?”, Applied Economics, Vol. 22 No. 8, pp. 1029-1038.

Kurkkio, M., Frishammar, J. and Lichtenthaler, U. (2011), "Where process development begins: a multiple case study of front end activities in process firms", Technovation, Vol. 31 No. 9, pp. 490-504.

Laforet, S. (2011), "A framework of organisational innovation and outcomes in SMEs", International Journal of Entrepreneurial Behavior \& Research, Vol. 17 No. 4, pp. 380-408.

Lam, A. (2005), "Organizational innovation", in Fagerberg, J., Mowery, D.C. and R. R. Nelson, R.R. (Eds.), The oxford handbook of innovation, Oxford University Press, Oxford, pp. 115-147.

Laursen, K. and Foss, N.J. (2003), "New human resource management practices, complementarities and the impact on innovation performance", Cambridge Journal of Economics, Vol. 27 No. 2, pp. 243-263.

Le Bas, Ch., Mothe, C. and Nguyen-Thi, T.U. (2015), "The differentiated impacts of organizational innovation practices on technological innovation persistence", European Journal of Innovation Management, Vol. 18 No. 1, pp. 110-127.

Lopez-Valeiras, E., Gonzalez-Sanchez, M.B. and Gomez-Conde, J. (2016), "The effects of the interactive use of management control systems on process and 
organizational innovation", Review of Managerial Science, Vol. 10 No. 3, pp. 487510.

McAdam, R., McConvery, T. and Amstrong, G. (2004), "Barriers to innovation within small firms in a peripheral location", International Journal of Entrepreneurial Behavior \& Research, Vol. 10 No. 3, pp. 206-221.

McKnight, B. and Ziestma, C. (2018), "Finding the threshold: A configurational approach to optimal distinctiveness", Journal of Business Venturing, Vol. 33 No. 4, pp. 493512.

Mol, M.J. and Birkinshaw, J. (2009), "The sources of management innovation: When firms introduce new management practices", Journal of Business Research, Vol. 62 No. 12, pp. 1269-1280.

Nahm, A.Y., Vonderembse, M.A. and Koufteros, X.A. (2003), "The impact of organizational structure on time-based manufacturing and performance", Journal of Operations Management, Vol. 21 No. 3, pp. 281-306.

Nguyen-Thi, T.U. and Mothe, C. (2010), "The link between non technological innovations and technological innovation”, European Journal of Innovation Management, Vol. 13 No. 3, pp. 313-332.

Nieves, J. (2016), "Outcomes of management innovation: Na empirical analysis in the services industry", European Management Review, Vol. 13 No. 2, pp. 125-136.

OECD (2005), Oslo manual - The measurement of scientific and technological activities: Proposed guidelines for collecting and interpreting technological innovation data. OECD, Paris.

Oke, A. (2013), "Linking manufacturing flexibility to innovation performance in manufacturing plants", International Journal of Production Economics, Vol. 143 No. 2, pp. 242-247.

Ordanini, A., Parasuraman, A. and Rubera, G. (2014), "When the recipe is more important than the ingredients a Qualitative Comparative Analysis (QCA) of service innovation configurations", Journal of Service Research, Vol. 17 No. 2, pp. 134149.

Pérez-Pérez, M., Bedia, A-M.S., López-Fernandez, M-C. and García-Piqueres, G. (2018), "Research opportunities on manufacturing flexibility domain: A review and theory-based research agenda", Journal of Manufacturing Systems, Vol. 48 A, pp. 9-20.

Piening, E.P. and Salge, T. O. (2015), "Understanding the antecedents, contingencies, and performance implications of process innovation: A dynamic capabilities perspective", Journal of Product Innovation Management, Vol. 32 No. 1, pp. 8097.

Pisano, G.P. and Wheelwright, S.C. (1995), "The new logic of high-tech R\&D”, Long Range Planning, Vol. 28 No. 6, pp. 128-128.

Podsakoff, P.M. and Organ, D.W. (1986), "Self-reports in organizational research: Problems and prospects", Journal of Management, Vol. 12 No. 4, pp. 531-544.

Podsakoff, P.M., MacKenzie, S.B. Lee, J.-Y. and Podsakoff, N.P. (2003), "Common method biases in behavioral research: A critical review of the literature and 
recommended remedies", Journal of Applied Psychology, Vol. 88 No. 5, pp. 879903.

Ragin, C.C. (2008), Redesigning social inquiry: Fuzzy sets and beyond, University of Chicago Press, Chicago.

Ragin, C.C. (2009), "Qualitative Comparative Analysis Using Fuzzy Sets (fsQCA)", in Ragin, C.C. and Rihoux, B. (Eds.), Configurational Comparative Methods: Qualitative Comparative Analysis (QCA) and Related Techniques, Sage, Los Angeles, pp. 87-122.

Rihoux, B., Rezsöhazy, I. and Bol, D. (2011), "Qualitative comparative analysis (QCA) in public policy analysis: An extensive review", German Policy Studies, Vol. 7 No. 3, pp. 9-82.

Rivkin, J.W. (2000), "Imitation of complex strategies", Management Science, Vol. 46 No. 6 , pp. 824-844.

Sapprasert, K. and Clausen, T. (2012), "Organizational innovation and its effects", Industrial and Corporate Change, Vol. 21 No. 5, pp. 1283-1305.

Schneider, C.Q. and Wageman, C. (2010), "Standards of Good Practice in Qualitative Comparative Analysis (QCA) and Fuzzy-Sets", Comparative Sociology, Vol. 9, No. 3, pp. 397-418.

Schneider, M.R., Schulze-Bentrop, C. and Paunescu, M. (2010), "Mapping the institutional capital of high-tech firms: A fuzzy-set analysis of capitalist variety and export performance", Journal of International Business Studies, Vol. 41 No. 2, pp. 246-266.

Schumpeter, J. (1934), The theory of economic development, Harvard University Press, Cambridge, MA.

Seebacher, G. and Winkler, H. (2014). "Evaluating flexibility in discrete in discrete manufacturing based on performance and efficiency", International Journal of Production Economics, Vol. 153, pp. 340-351.

Simonetti, R., Archibugi, D., Evangelista, R. (1995), "Product and process innovations: how are they defined? How are they quantified?", Scientometrics, Vol. 32 No. 1, pp. 77-89.

Simpson, P.M., Siguaw, J.A. and Enz, C.A. (2006), "Innovation orientation outcomes: the good and the bad", Journal of Business Research, Vol. 59 No. 10-11, pp. 11331141.

So, K.K.F., King, C., Sparks, B.A. and Wang, Y. (2013), "The influence of customer brand identification on hotel brand evaluation and loyalty development", International Journal of Hospitality Management, Vol. 34, pp. 31-41.

Som, O., Diekmann, J., Solberg, E., Schricke, E., Schubert, T., Jung-erceg, P., et al. (2012), Organizational and marketing innovation — promises and pitfalls? PRO INNO Europe: INNO-Grips II report. European Commission, DG Enterprise and Industry, Brussels.

Stadler, C. (2011), "Process innovation and integration in process-oriented settings: the case of the oil industry", Journal of Product Innovation Management, Vol. 28 No. 1, pp. 44-62. 
Stam, E. and Wennberg, K. (2009), "The roles of R\&D in new firm growth", Small Business Economics, Vol. 33 No. 1, pp. 77-89.

Torres, P. and Augusto, M. (2019), "Cultural configurations and entrepreneurial realisation", International Journal of Entrepreneurial Behavior \& Research, Vol. 25 No. 1, pp. 112-128.

Trist, E. and Bamforth, K. (1951), "Some social and psychological consequences of the longwall method: An examination of psychological situation and defences of a work group in relation to the social structure and technological content of the work system", Human Relations, Vol. 4 No. 1, pp. 3-38.

Utterback, J.M. and Abernathy, W.J. (1975), “A dynamic model of process and product innovation”, Omega, Vol. 3 No. 6, pp. 639-656.

Vaccaro, I.G., Jansen, J.J.P., Van Den Bosch, F.A.J. and H.W. Volberda, H.W. (2012), "Management Innovation and Leadership: The Moderating Role of Organizational Size", Journal of Management Studies, Vol. 49 No. 1, pp. 28-51.

Visnjic, I., Wiengarten, F. and Neely, A. (2016), "Only the brave: Product innovation, service business model innovation, and their impact on performance", Journal of Product Innovation Management, Vol. 33 No. 1, pp. 36-52.

Wei, Z., Song, X. and Wang, D. (2017), "Manufacturing flexibility, business model design, and firm performance", International Journal of Production Economics, Vol. 193, pp. 87-97.

Wong, P.K., Lee, L. and Foo, M.D. (2008), "Occupational choice: the influence of product vs. process innovation”, Small Business Economics, Vol. 30 No. 3, pp. 267-281.

Wong, S.K.S. (2013), “The role of management involvement in innovation”. Management Decision, Vol. 51 No. 4, pp. 709-729.

Yu, K., Cadeaux, J. and Luo, B.N. (2015), "Organizational flexibility: review and metaanalysis", International Journal of Production Economics, Vol. 169 C, pp. 190202. 
Table 1. Scale items and Cronbach's alpha coefficients

\begin{tabular}{|c|c|c|}
\hline Construct & Items & Cronbach's $\alpha$ \\
\hline $\begin{array}{l}\text { Manufacturing } \\
\text { flexibility } \\
\text { (FLEX) }\end{array}$ & $\begin{array}{l}\text { My firm is able to effectively increase or decrease aggregate } \\
\text { production in response to customers' demands. } \\
\text { My firm has a manufacturing system that is able to } \\
\text { effectively produce a wide variety of different products. } \\
\text { My firm has a manufacturing system that is able to } \\
\text { effectively handle additions to and subtractions from the } \\
\text { product mix over time. } \\
\text { My firm has a manufacturing system that is able to } \\
\text { effectively implement minor changes in current products } \\
\text { resulting from corrective actions or changing customer } \\
\text { requirements. } \\
\text { Source: Camisón and López (2010). }\end{array}$ & .82 \\
\hline $\begin{array}{l}\text { Product innovation } \\
\text { (PROD) }\end{array}$ & $\begin{array}{l}\text { My firm is able to replace obsolete products. } \\
\text { My firm is able to extend the range of products. } \\
\text { My firm is able to develop environmental friendly products. } \\
\text { My firm is able to improve products' design. } \\
\text { My firm is able to reduce the time to develop a new product } \\
\text { until it is launched to the market. } \\
\text { Source: Camisón and López (2010). }\end{array}$ & .80 \\
\hline $\begin{array}{l}\text { Process innovation } \\
\text { (PROC) }\end{array}$ & $\begin{array}{l}\text { My firm is able to create and manage a portfolio of } \\
\text { interrelated technologies. } \\
\text { My firm is able to master and absorb the basic and key } \\
\text { technologies of business. } \\
\text { My firm continually develops programs to reduce } \\
\text { production costs. } \\
\text { My firm has valuable knowledge for innovating } \\
\text { manufacturing and technological processes. } \\
\text { My firm has valuable knowledge on the best processes and } \\
\text { systems for work organization. } \\
\text { My firm organizes its production efficiently. } \\
\text { My firm assigns resources to the production department } \\
\text { efficiently. } \\
\text { My firm is able to maintain a low level of stocks without } \\
\text { impairing the service. } \\
\text { My firm is able to offer environmental friendly processes. } \\
\text { My firm manages the production organization efficiently. } \\
\text { My firm is able to integrate production management } \\
\text { activities. } \\
\text { Source: Camisón and López (2010). }\end{array}$ & .92 \\
\hline $\begin{array}{l}\text { Organizational } \\
\text { innovation } \\
(\text { ORG) }\end{array}$ & $\begin{array}{l}\text { Use of databases of best practices, lessons, and other } \\
\text { knowledge. } \\
\text { Implementation of practices for employee development and } \\
\text { improving worker retention. } \\
\text { Use of quality-management systems. } \\
\text { Decentralization in decision making. } \\
\text { Use of inter-functional working groups. } \\
\text { Flexible job responsibilities. } \\
\text { Collaboration with customers. } \\
\text { Use of methods of integration with suppliers. } \\
\text { Outsourcing of business activities. } \\
\text { Source: Camisón and López (2010). }\end{array}$ & .92 \\
\hline
\end{tabular}


Table 1. Scale items and Cronbach's alpha coefficients (cont.)

\begin{tabular}{ll}
\hline $\begin{array}{l}\text { Organizational } \\
\text { Performance }\end{array}$ & Market share growth. \\
(PERF) & Customers' satisfaction. \\
& Customers' retention. \\
& Works' productivity. \\
& Return on assets. \\
& Mean sales profitability. \\
& Source: Adapted from Nahm et al. (2003) and Camisón and \\
& López (2010). \\
\hline
\end{tabular}


Table 2. Analysis of necessary conditions for high and low performance

\begin{tabular}{lllll}
\hline & \multicolumn{2}{c}{ PERF } & \multicolumn{2}{c}{$\sim$ PERF } \\
\cline { 2 - 5 } & $\mathrm{C} 1$ & $\mathrm{C} 2$ & $\mathrm{C} 1$ & $\mathrm{C} 2$ \\
\hline PROD & .749 & .754 & .536 & .496 \\
$\sim$ PROD & .499 & .538 & .734 & .729 \\
PROC & .746 & .757 & .522 & .488 \\
$\sim$ PROC & .495 & .530 & .740 & .729 \\
ORG & .734 & .762 & .520 & .497 \\
$\sim$ ORG & .516 & .539 & .751 & .722 \\
\hline
\end{tabular}

Note: $\mathrm{PROD}=$ Product innovation; $\mathrm{PROC}=$ Process innovation $; \mathrm{ORG}=$ Organizational innovation; PERF = Performance; $\mathrm{C} 1=$ Consistency, and $\mathrm{C} 2=$ Raw coverage. The tilde “ ” represents negation. 
Table 3. Configurations leading to high and low performance

\begin{tabular}{lcccc}
\hline Configuration & PERF1 & $\sim$ PERF1 & $\sim$ PERF2 & $\sim$ PERF3 \\
\hline PROD & - & & $\otimes$ & $\otimes$ \\
PROC & & $\bigotimes$ & & $\bigotimes$ \\
ORG & $\bullet$ & $\bigotimes$ & $\otimes$ & \\
\hline C1 & .857 & .798 & .803 & .806 \\
C2 & .617 & .639 & .596 & .629 \\
C3 & .617 & .087 & .044 & .077 \\
\hline Overall C1 & .857 & & .753 & \\
Overall C2 & .617 & & .761 & \\
\hline
\end{tabular}

Note: $\mathrm{PROD}=$ Product innovation $; \mathrm{PROC}=$ Process innovation $; \mathrm{ORG}=$ Organizational innovation; $\mathrm{PERF}=$ Performance $\mathrm{C} 1=$ Consistency; $\mathrm{C} 2=$ Raw coverage, and $\mathrm{C} 3=$ Unique coverage. Black circles (“• ") indicate the presence of a condition; circles with a cross-out (" $\otimes$ ") indicate its absence; blank spaces indicate "don’t care”. The tilde “ ” represents negation. 
Table 4. Analysis of necessary conditions for high and low product innovation

\begin{tabular}{lllll}
\hline & \multicolumn{2}{c}{ PROD } & \multicolumn{2}{c}{$\sim$ PROD } \\
\cline { 2 - 5 } & $\mathrm{C} 1$ & $\mathrm{C} 2$ & $\mathrm{C} 1$ & $\mathrm{C} 2$ \\
\hline FLEX & .776 & .810 & .488 & .474 \\
$\sim$ FLEX & .496 & .510 & .805 & .770 \\
PROC & .782 & .789 & .495 & .465 \\
$\sim$ PROC & .470 & .500 & .776 & .769 \\
ORG & .724 & .748 & .519 & .499 \\
$\sim$ ORG & .515 & .535 & .738 & .713 \\
\hline
\end{tabular}

Note: FLEX $=$ Manufacturing flexibility PROD $=$ Product innovation; $P R O C=$ Process innovation; $\mathrm{ORG}=$ Organizational innovation; $\mathrm{C} 1=$ Consistency, and $\mathrm{C} 2=$ Raw coverage. The tilde “ " represents negation. 
Table 5: Configurations leading to high and low product innovation

\begin{tabular}{|c|c|c|c|}
\hline Configuration & PROD1 & PROD2 & $\sim$ PROD1 \\
\hline $\begin{array}{l}\text { FLEX } \\
\text { PROC } \\
\text { ORG }\end{array}$ & 7 & $\mathrm{C}$ & $\begin{array}{l}\otimes \\
\otimes\end{array}$ \\
\hline $\mathrm{C} 1$ & .893 & .879 & .871 \\
\hline $\mathrm{C} 2$ & .651 & .600 & .664 \\
\hline $\mathrm{C} 3$ & .103 & .052 & .664 \\
\hline Overall C1 & \multicolumn{2}{|c|}{.870} & .871 \\
\hline Overall C2 & \multicolumn{2}{|c|}{.703} & .664 \\
\hline
\end{tabular}

Note: $\mathrm{PROD}=$ Product innovation; FLEX = Manufacturing flexibility; $\mathrm{PROC}=$ Process innovation $\mathrm{ORG}=$ Organizational innovation $\mathrm{C} 1=$ Consistency $; \mathrm{C} 2=$ Raw coverage, and $\mathrm{C} 3=$ Unique coverage Black circles ("• ") indicate the presence of a condition; circles with a cross-out (" $\otimes$ ") indicate its absence; blank spaces indicate "don't care". The tilde “ " represents negation. 
Table 6: Summary of the results

\begin{tabular}{l} 
Tenets \\
\hline Regarding high and low performance \\
T1.1. The presence or the absence of a simple \\
antecedent condition (product innovation, process \\
innovation, and organizational innovation) is \\
neither necessary nor sufficient to obtain the \\
outcome condition (performance).
\end{tabular}

T1.2. A combination of organizational innovation with one form of technological innovation (product or process innovation) can be sufficient to achieve high levels of performance.

T1.3. Combinations of antecedent conditions that lead to low performance, are not necessarily the mirror opposites of complex conditions (i.e., configurations), leading to high performance.

\section{Regarding high and low product innovation}

T2.1. The presence or the absence of a simple antecedent condition (organizational innovation, process innovation, and manufacturing flexibility) is neither necessary nor sufficient to obtain the outcome condition (product innovation).

T2.2. A combination of manufacturing flexibility with either organizational or process innovation can be sufficient to achieve high levels of product innovation.

T2.3. Combinations of antecedent conditions that lead to low product innovation, are not necessarily the mirror opposites of complex conditions (i.e., configurations) leading to high product innovation.

\section{Results}

Supported: Each antecedent condition on its own is not necessary nor sufficient for the outcome (high levels performance) to occur.

Supported: The joint presence of organizational innovation and product innovation is sufficient for the outcome (high levels of performance) to occur.

Supported: There are three equifinal configurations for low levels of performance, which indicates causal asymmetry.

Supported: Each antecedent condition on its own is not necessary nor sufficient for the outcome (high levels product innovation) to occur.

Supported: The joint presence of manufacturing flexibility with either organizational innovation or process innovation is sufficient for the outcome (high levels of product innovation) to occur.

Supported: There is only one configurations leading to low levels of product innovation, which indicates causal asymmetry. 